\title{
Sustainability impact of tall buildings: thinking outside the box!
}

\author{
A. Aminmansour \\ University of Illinois at Urbana-Champaign, USA
}

\begin{abstract}
Tall buildings are not intrinsically sustainable. They consume a higher rate of construction material per unit floor area; have a higher rate of energy consumption and are considered to be less economical than their shorter counterparts. However, while such analyses may be correct in a literal sense, a more wide-ranging and holistic examination of tall buildings points to the fact that they do indeed contribute considerably to the sustainability of our environment. The key is that, unlike low rise buildings, the sustainability impact of tall buildings reaches far beyond their physical boundaries. This paper offers a broad review of the facts surrounding sustainability impact of tall buildings in the urban and suburban context. It provides a comprehensive overview of consumption of structural and other materials and resources; impact on infrastructure; reduced generation of pollution; overall economy; improved quality of life and benefits to the society. A comprehensive study of such factors will not only help develop a better understanding of the true sustainability impact of tall buildings, but offer a means for better promotion of tall buildings as having a considerable positive influence on our environment and quality of life in an urban context.
\end{abstract}

Keywords: sustainability, tall buildings, urban, suburban, integrated design.

\section{Urbanization and tall buildings}

Development of tall buildings has seen a considerable growth over the last several years. This increase, however, cannot be solely attributed to the increase in the world population. There is a rush to build tall buildings and more of them.

Several factors other than population growth contribute to the more development of tall buildings. They include the high cost and limited availability 
of land in urban areas as well as the desire to move to large city centres where population density and large concentrated business districts offer enhanced career opportunities and a better life-style for many.

The Council on Tall Buildings and Urban Habitat (CTBUH [1]) reports that the global rate of urbanization is at about 200,000 people every day. If this trend continues, it is very possible that the population of a number of mega metropolitan areas may reach or even exceed 50 million by the year 2050. Asia appears to be leading this high rate of urbanization.

More and more people are moving from the suburbs to residential towers in large city centres. According to CTBUH, $12 \%$ of the 100 tallest buildings in the world were mixed-use in the year 2000. That same year, none of the 100 tallest buildings were entirely residential. In contrast, in the year 2012, about 53\% of the 100 tallest buildings in the world were either mixed-use or entirely residential.

Tall buildings are often viewed as attractive by the public and reflect signs of progress and financial prosperity. After all, the skyline of numerous cities around the world known for prosperity and global financial impact are filled with tall buildings. Examples of such cities include New York, Toronto, Busan, Hong Kong, Shanghai and Singapore (Figure 1).

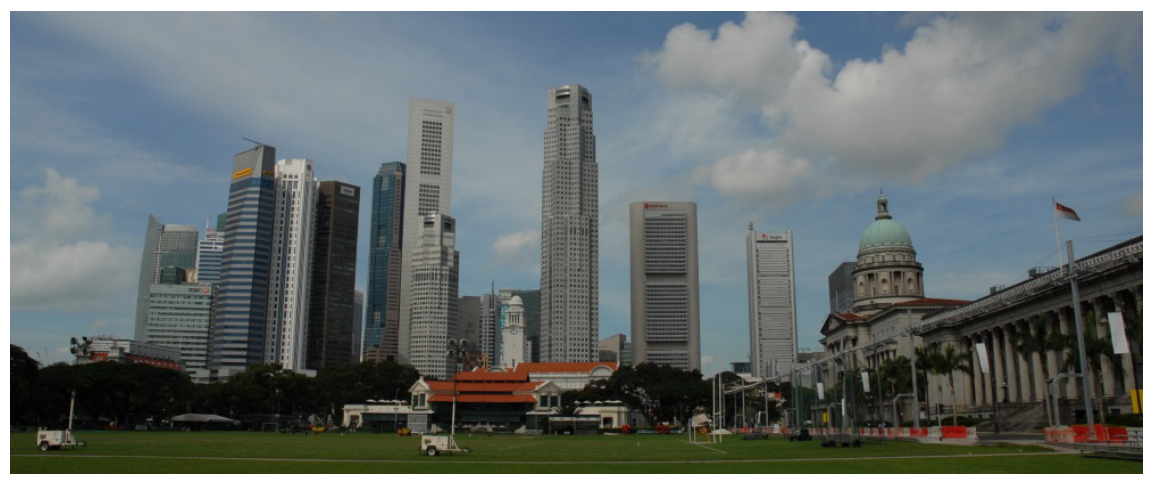

Figure 1: $\quad$ Skyline of Singapore business district.

As noted earlier, Asia is at the forefront of the race to urbanization. However, the growth of the number of tall buildings in this continent is considerably larger than its population increase. According to CTBUH, the world's population increased from 6,115,000,000 in year 2000 to 6,908,000,000 in year 2011, reflecting an increase of about $13 \%$ over this period. However, over the same period, the number of buildings 200 meters (656 feet) or taller increased from 258 to 602 , an increase of $133 \%$.

According to CTBUH statistics, the number of high rises 200 meters or more increased at a rate of about 10 times that of the world population growth over the 2000-2011 period. And again, Asia has the global lead (64\%) for construction of new buildings 200 meters or taller completed in 2010 alone (Figure 2). The Middle-East came in second with $21 \%$ of the 200 meters or taller buildings. 


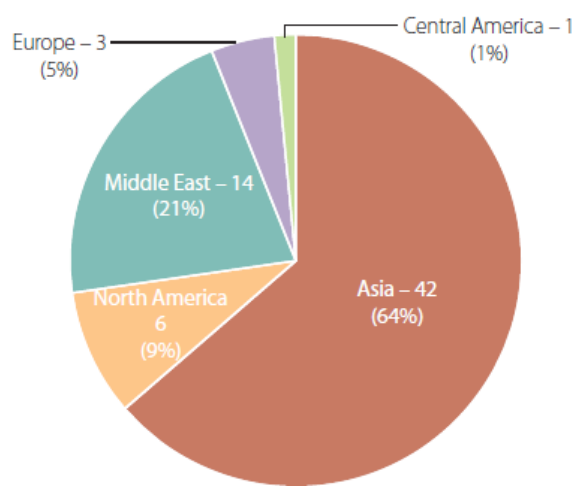

Figure 2: $\quad$ Buildings 200 meters or taller completed in 2010 (obtained from CTBUH [1]).

China which has less than $20 \%$ of the world population has over $33 \%$ of buildings 200 meters or taller world-wide. According to CTBUH (CTBUH [2]), 16 of the 20 tallest buildings in the world are in Asia with 11 being in China. Twenty-one of the 66 buildings 200 meters or taller completed in 2010 are in China. . The United Arab Emirates (UAE), with a population of only about $0.1 \%$ of the world, has the second but an impressive rate with $7.7 \%$ of the 200 meters or taller buildings in the world. And the heights get taller and taller. Eight super tall buildings were completed in 2010 worldwide, more than any previous year.

\section{Are tall buildings "sustainable"?}

Intrinsically, tall buildings are not sustainable in-and-of-themselves. However, they can have a considerable sustainability impact in the urban and suburban context. We just need to look at their impact outside the box, literally.

Tall buildings require more construction material per unit floor area. The lateral load resisting system is the dominant structural system in tall buildings, not the gravity load resisting system. And there is a "premium for height." The taller you go, the higher the premium. Figure 3, obtained from the Princeton University web site (Princeton [3]), and originally adopted from diagram of Yasmin Khan (Khan [4]), represents a graphical illustration of this premium. Curve (a) in Figure 3 represents the amount of theoretical gravity load resisting structural system needed for tall buildings of different heights. Curve (b), on the other hand, represents the amount of total structure needed including gravity and lateral load resisting system for tall buildings. The shaded area represents the premium for height. As an example, note that a 100-storey building requires about $160 \%$ more steel per unit area due to its lateral load resisting system than what is needed for gravity loads alone. This increase in material use requires more of our available resources and increases the Carbon-footprint of tall buildings considerably. In order to reduce the premium for height, it is critical 


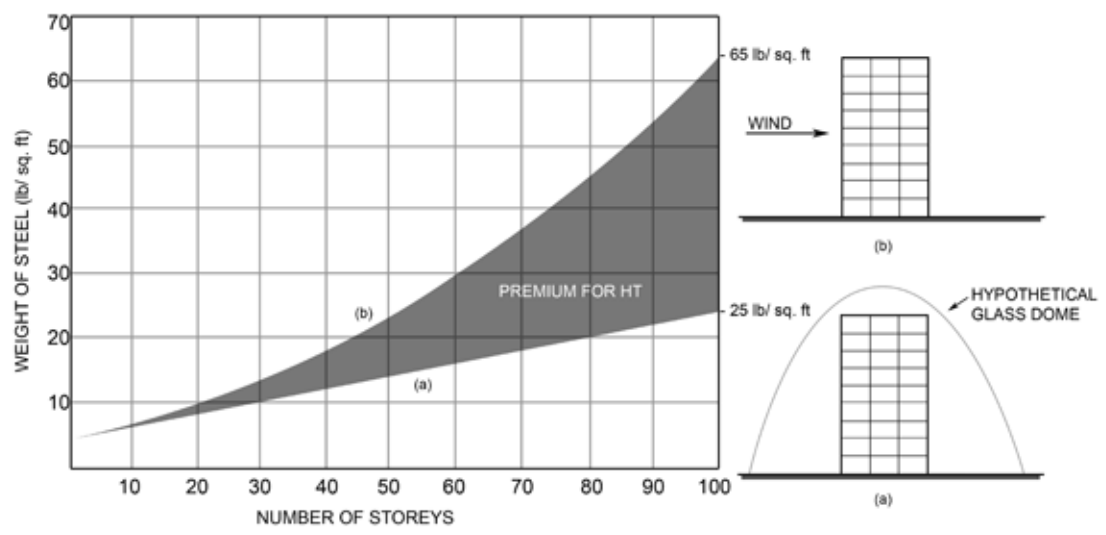

Figure 3: Premium for Height created by Fazlur Khan (obtained from Princeton [3]).

that the most appropriate structural system is selected for a particular tall building (Ali and Moon [5]).

From an energy consumption point of view, again, tall buildings do not fare well when compared to their shorter counterparts. Tall buildings often encompass innovative architecture and have a significant amount of glazing in their curtain walls. This feature too, increases the energy consumption and Carbon-footprint of tall buildings. When compared to shorter buildings, tall buildings consume more energy for heating or cooling per unit floor area or per volume of building than shorter buildings do. As of today, there are no economical and practical transparent materials that are as efficient in terms of their thermal properties as regular insulated wall.

A considerable amount of floor space in tall buildings is taken up by elevator shafts and building services core, reducing the "usable" floor area. This characteristic as well as the fact that elevators consume energy to operate decrease the "sustainability" of tall buildings. Needless to say, elevators are an essential and necessary tool in tall buildings.

There are other characteristics of tall buildings that make them less "sustainable". Delivering needed resources such as water and conditioned air to tall heights in high rise buildings require more energy than in lower rise buildings.

\section{Quick overview of "sustainability" of buildings}

While there are numerous definitions of "sustainability," there is a common thread among different interpretations of the word. It is universally agreed that sustainability includes concern for the environment including judicious use of our limited natural resources and considerations for cutback in or elimination of 
production of material that may be harmful to our health and to the environment. In addition, economy and social issues are considered as among other metrics in evaluation of sustainability of a building.

At times, people associate sustainable development with sacrifices in our lifestyle and feeling of well-being. That is not true. Neither should sustainable design lead to buildings that are uneconomical to design, construct or operate. Indeed improving human lifestyle and enhanced long term economy must remain among central goals of sustainable development (Aminmansour [6]).

\section{4 “Sustainability impact" of tall buildings}

As noted earlier, tall buildings are not sustainable in-and-of-themselves, but have a considerable "sustainability impact" in the urban context. To illustrate this point, an example of a tall residential tall building is studied below.

Consider a tall building in a large city with 400 residential units. An alternative to this compact collection of residences is spreading them as singlefamily dwellings in the suburb. The infrastructure needed to support 400 residences in the suburb is significantly large. There needs to be a considerable amount of roads to support residences requiring significant amount of material and maintenance and increases the Carbon-footprint of these residences. Delivering water, electricity and sewer services to these 400 residences too will require substantial material and will increase the Carbon-footprint of the residences. In addition, very likely a good portion of residents of these dwellings will need to commute to the city and back for work and business. This results in a considerable amount of time spent on the road reducing people's timeefficiency plus wear-and-tear of vehicles, additional expense, fuel consumption and generating additional pollution as opposed to if the residents lived in the city to begin with.

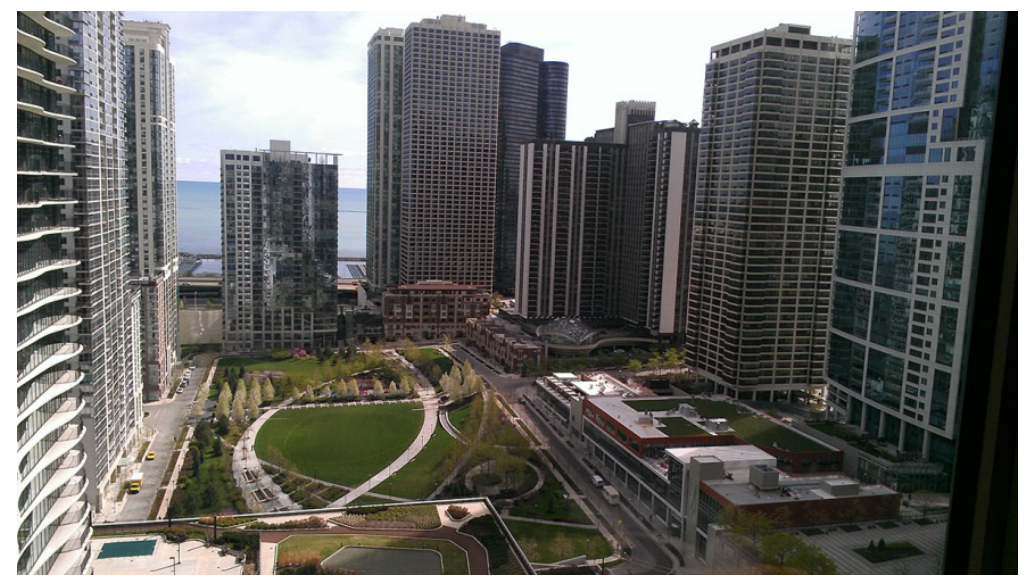

Figure 4: $\quad$ Park in downtown Chicago in the midst of numerous towers. 
Some view large city centres as an area dense with numerous tall buildings with no place for nature and hard to get around. Indeed with appropriate planning, large city centres may offer parks and recreation centres in the midst of a business district (Figure 4). Further, they can accommodate easy navigation of pedestrians (Figure 5).

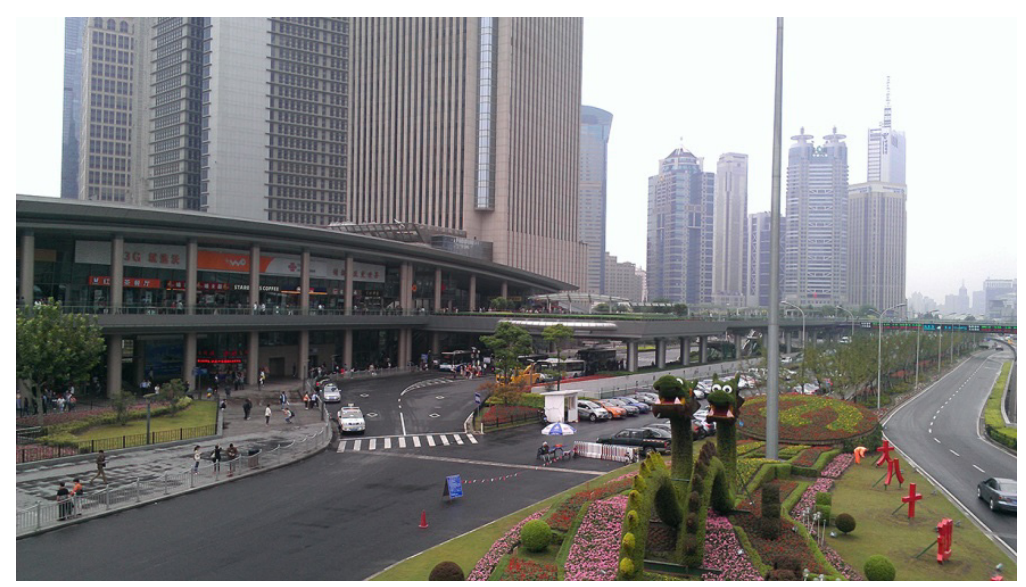

Figure 5: Shanghai business district with elevated pedestrian pathways to avoid conflict with vehicular traffic.

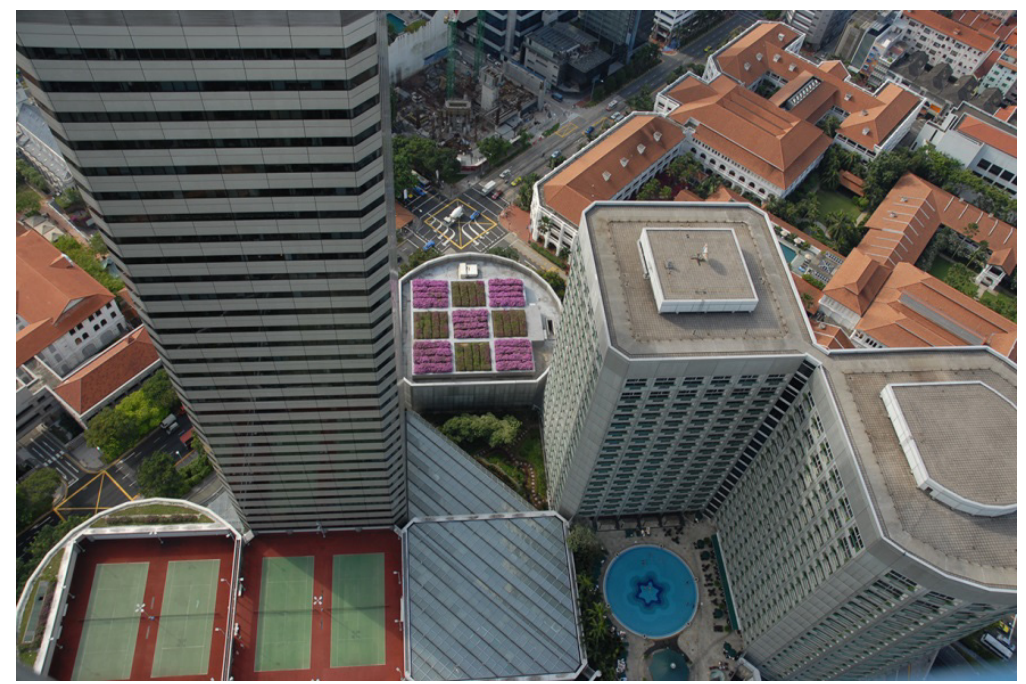

Figure 6: Gardens, swimming pools and tennis courts on roofs of tall buildings in Singapore to enhance quality of life. 
An aspect of sustainability that is often overlooked is human wellness including happiness. As noted earlier, indeed improving human lifestyle and enhanced long term economy must remain among central goals of sustainable development (Aminmansour [6]). Many people including young professionals as well as retired elderly prefer the life-style offered in large city centres and will be happier when they are closer to work or places for dining and entertainment. Further, gardens, swimming pools and sport facilities may be appropriately incorporated on roofs of tall buildings in business districts to enhance quality of life and provide healthier environment (Figure 6).

\section{Conclusion}

Tall buildings in-and-of-themselves are not "sustainable" when compared to low rise buildings. However, they do have a considerable "sustainability impact" within the urban and suburban context. However, there is a need for quantifying this impact thru additional research.

\section{Future research}

The author is currently engaged in research to quantify many of the general points made in this paper. Those results will be published in the future.

\section{Credits}

All photographs included in the paper were taken by the author.

\section{References}

[1] Council on Tall Buildings and Urban Habitat (CTBUH) web site. www.ctbuh.org.

[2] Council on Tall Buildings and Urban Habitat (CTBUH), Tall Buildings in Numbers, CTBUH Review, pp. 44-45, Issue I, 2011.

[3] Princeton University, Fazlur Khan, Structural Artist of Urban Building Form. http://khan.princeton.edu/khanHancock.html.

[4] Khan, Yasmin Sabina, Engineering Architecture: the Vision of Fazlur R. Khan. New York: W.W. Norton, 2004.

[5] Ali, Mir and Moon, K.S., Structural Developments in Tall Buildings: Current Trends and Future Prospects, Architectural Science Review. Volume 50.3, pp. 205-223, 2007.

[6] Aminmansour, A., Overview of Tall Buildings and Their Sustainability Impact. Proceedings of the Research, Development, and Practice in Structural Engineering and Construction conference, ASEA-SEC-1, 2012. 